\title{
Abortion: Thinking Clearly About Controversial Public Policy
}

\author{
Fred Nunes
}

One of the main impediments to reasoned discussion of abortion law reform is the absence of a clear, simple overarching framework for informing public policy. Lacking such a frame, discussions quickly become dichotomous and position-based. Language polarises and divides rather than inform and unite. The notes and diagrams below are intended to contribute to the development of a basis for meaningful conversations in this sensitive and controversial arena.

It may be helpful to begin with a few questions:

1. Do restrictive abortion laws secure a reduction in abortions?

2. How well do criminal abortion laws protect the sanctity of life?

3 Are restrictive laws equitable across all classes of women?

4. Do liberal abortion laws result in a weakening of the moral fabric of society?

5. Do liberal abortion laws result in an explosion of abortions?

6. How does either approach affect the physical and emotional health of women?
In other words, how well do laws, whether restrictive or liberal, serve our moral standards and social goals of the sanctity of life, family, safe motherhood, autonomy, justice, fairness and equity?

I would like to be as sparse as possible in commentary and keep to the simplicity of the diagrams. In this effort, let me confess that the diagrams, like any picture of reality, are an oversimplification. This is intentional. My purpose is to reduce the experience to one we can readily see, feel and experience. I accept responsibility for any distortion although none is intended.

Let me begin with a description of the social situation the path for a young person that might lead to an unwanted pregnancy (Figure 1). Let us start at Step 1 with the moral values and social attitudes. These are the considerations that guide our decisions and behaviour. As we all know, our values don't fall from the sky. They are nurtured by our early models and experiences, by the lessons we hear and the behaviour we see in our families, our religious institutions, our friends, schools, the games and entertainment we enjoy and how we live in our communities. 


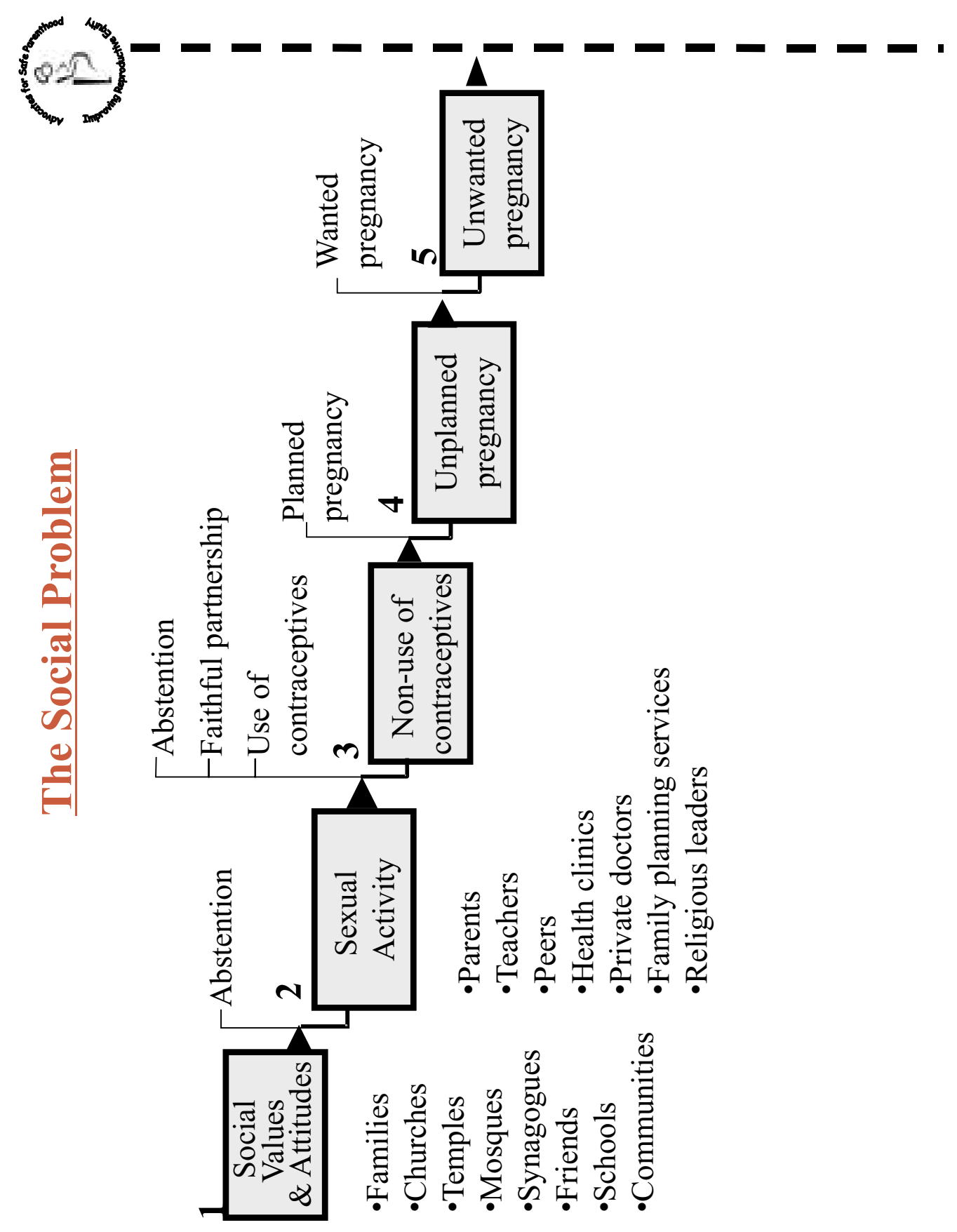


If these are all wholesome, consistent and reinforcing there is a real chance that they will have a great influence on how we behave. But to the extent that we receive conflicting messages and see gaps between what people say and how they behave, then we too may fall short of the high standards expected of us.

We know that our religious institutions are pivotal in nurturing moral precepts in each of us. If young people hold strictly to these moral codes then we would expect them to abstain from sexual activity until they have formed a stable union. For this group, all is well.

However, if they wander beyond those codes, we see that at Step 2 they are likely to engage in sexual activity well before they have any intention of forming a stable relationship. At his point, while all the moral teachings, nurturing and inculcation remain in place, there is also a need for a different for of guidance. They need information about sexuality from persons they can trust their parents, teachers, health personnel and, hopefully, religious leaders. They are also likely to consult their peers. The quality of guidance they receive is likely to be heavily influenced by the general openness about sexuality in their community. To the extent that sex is readily discussed between parents and children, information is likely to be readily available. If it is not, what peers know may be highly unreliable.

Once the young person is armed with this information, he or she may decide on a course of abstention, commit to a faithful, monogamous relationship or rely on contraceptives. This behaviour may be the result of value-driven religious instruction and faith or information-driven as a result of knowledge and education gained about sexuality. Whatever the cause, all would be well for this person.

If our young friend chooses to ignore both the moral instruction and information about sexuality, then he or she is likely to continue on a venture of sexual activity without either moral rails or reliable forms of fertility prevention. This takes us to Step 3 and we are further down the path of the social problem we would all rather avoid.

The net result of this course of action will almost certainly be a pregnancy. If the pregnancy were planned then of course it is welcomed with great joy and hopefully all goes well.

But the pregnancy may be unplanned and that puts us at Step 4. How the couple responds to an unplanned pregnancy is critical. An unplanned pregnancy can be a huge wake-up call. The couple can take it in their stride and consolidate a relationship. In other words, an unplanned pregnancy can nevertheless be a wanted pregnancy.

Or the couple can realise that they are not in any way ready for the responsibility of parenthood. If their reaction is such that the unplanned pregnancy is also unwanted, we move along to Step 5 .

It is here finally that the couple together, or the woman alone encounters the force of the law. We have depicted the law by a vertical, dotted line. We should note that in tracing the social problem, prior to this point the law has not been a consideration. 


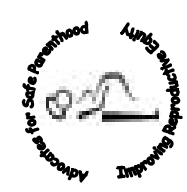

|
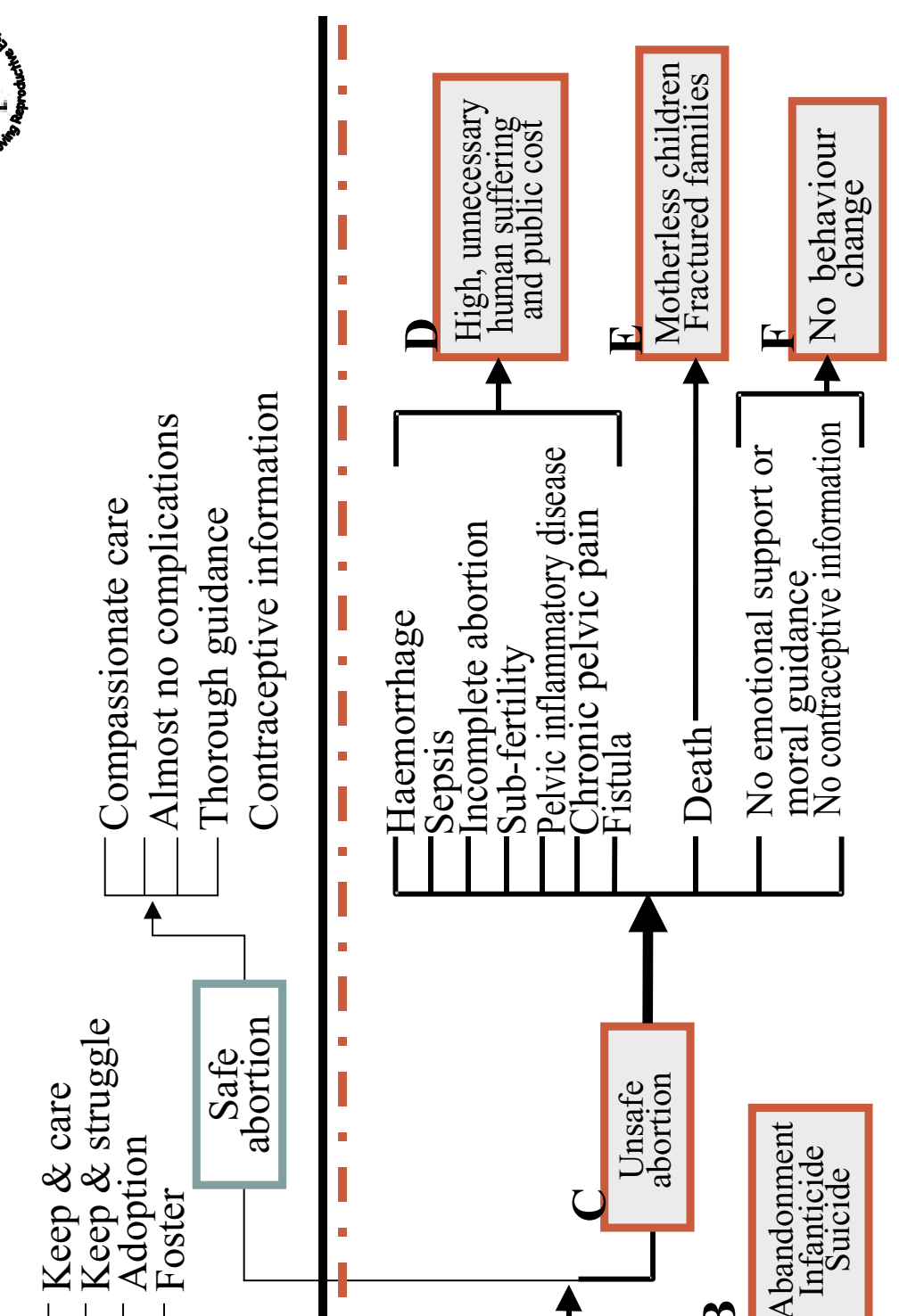

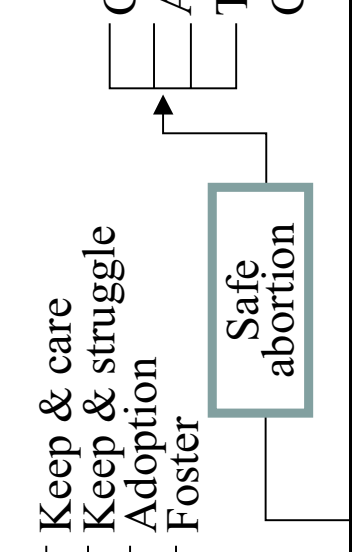

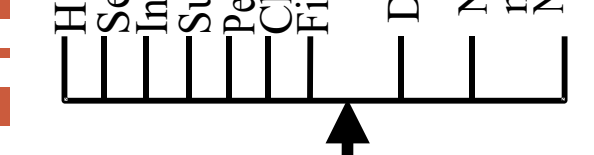
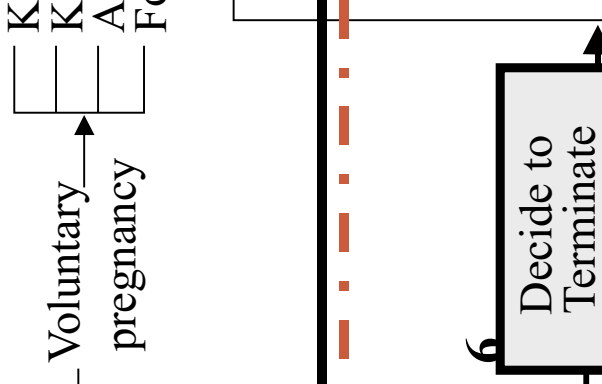
In all of this we have made the convenient assumption that sexual activity is entirely voluntary. We know that this is often not the case, especially so among young women and even more so among poor young women. But let us ignore that complication.

What we have tried to portray is the social situation that gives rise to unwanted pregnancy. Let us now turn to our current restrictive law and see how it impacts on women with unwanted pregnancies (Figure 2).

We begin with the dotted line representing the restrictive or criminal abortion law on the left of our diagram. I would like us to look at a few decision points and then identify the range of consequences.

As we see it, the woman has three options. In spite of not wanting the pregnancy, she can choose voluntarily to carry the pregnancy. If this is a well-informed decision then the outcome will probably be a satisfactory one. She may keep and care for the child even if she has to overcome real social and economic obstacles in doing so. Or she may put it in a foster home until she can care for it, or she may give it up for adoption. These are all outcomes that are generally acceptable in our society, however painful for any one individual.

Her second course of action may be an involuntary pregnancy. In other words, her own preference is to terminate the pregnancy, but she is coerced against her own judgment to continue with it. This puts us at Impact A. She may feel trapped by her own high religious value for life or by pressure from her family and friends, and the social stigma of abortion to carry her pregnancy to term.

This situation is one disposed to tension and difficulty. All may turn out well the moment the mother sees her child. But it may not. This takes us to Impact B. The worst case scenarios we have depicted include abandonment, infanticide and suicide. None of these tragic outcomes is unknown to us.

The third course of action is where the woman decides to terminate her pregnancy. This is Step 6. In much of the world, something in the order of $40 \%$ of pregnancies are unplanned and about a half of them end in abortions. We are dealing with a major phenomenon, not a minor aberration. This is the social reality under our 'criminal law of abortion.'

Once the woman decides to end her pregnancy she is faced with two very different paths depending on her social and economic circumstances.

If she has the means to afford the services of a private medical practitioner then she can readily have access to a safe abortion. She will face few questions and she can be confident of being free of complications. Under the best possible conditions she may also enjoy compassionate care and benefit from excellent counselling regarding contraceptives. Her dignity will be preserved.

Again, we confess to exaggerating the quality of this service. Standards vary among private practitioners. This is an unregulated service, conducted beyond the scrutiny of the Medical Council. What we have described is undoubtedly 'best practice.' 
We pause to note that the criminal law is not a bar on any woman of means who wants to end a pregnancy. Even in the most restrictive environments women with money can travel abroad to countries where legal, high quality services are available.

If the woman is too poor to afford a medical practitioner and yet is still determined to end her pregnancy, she takes recourse to an unsafe provider. We are at Impact C. The fact that millions of women put their lives at risk every year to have unsafe abortions should give us cause to appreciate how determined they are to control their fertility. They are truly desperately determined. Many of them are lucky and suffer no physical consequences requiring hospitalisation. Many others, not so fortunate face the horrendous sequelae of unsafe abortion.

We have listed only a few of these haemorrhage, sepsis, incomplete abortion, sub-fertility, sometimes infertility, pelvic inflammatory disease, chronic pelvic pain and fistula. Together these result in Impact $\mathrm{D}$, enormous unnecessary human suffering and high, equally unnecessary public hospital costs.

One of the perverse aspects of the criminal law is that doctors in public hospitals cannot easily admit women who want a termination and provide that service for fear of being in breach of an unclear law. But as soon as those same women have damaged themselves, those same doctors are then obliged to admit them and care for them at far greater public cost.
Of course, one other possible outcome of an unsafe abortion is death. One might assume that would be the end of the line. But it is not, not if one looks to the family, as we do in Impact E. The woman may leave children without effective parental care. If she has girls, they could be vulnerable to the same cycle that she has lived and died. She is unavailable to guide them.

Finally we come to the other aspect of law. We have established that it certainly does not prevent abortions. Does it change behaviour? In our view, it does not. We show this at Impact F. In the public hospitals that care for women with complications of unsafe abortion, there is no provision for counselling or for contraceptive information. There is no investment in the emotional or informational support that would be required to achieve behaviour change. As a result about half of the abortions in poor countries every year are repeat abortions. This appalling failure of the law to influence behaviour is perhaps its worst legacy.

Looked at as a whole, an ugly picture emerges. We have one law but two distinct worlds. One is a world that lives above the law and enjoys easy access to safe private medical care. The other is a poor world in which women risk their lives and taxpayers pick up the tab in unnecessarily high hospital costs. The criminal law is a source of gross social injustice. We have depicted this ugly stratification by a solid horizontal black line and a broken line. Some live comfortably and secretively above the law, while other bleed quietly below it. 
Abortion: Thinking clearly about controversial public policy
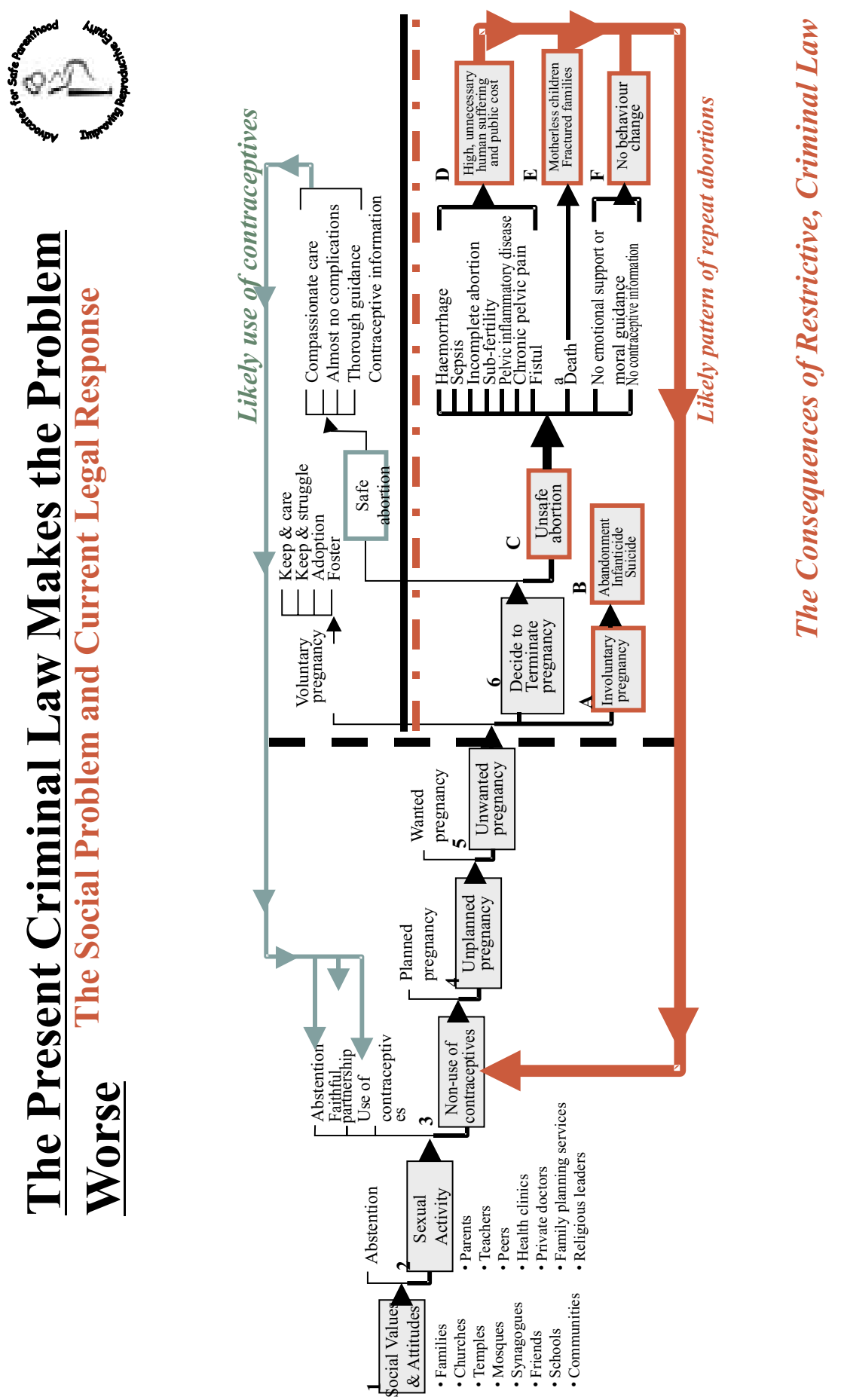
Let us put these two elements together, the social problem we considered earlier and the criminal law (Figure 3).

We see that if good quality care is provided to women who are able to afford private medical services, they are likely to use contraceptives and they may well adopt behaviours consistent with abstention, or faithful partnerships. This is depicted by the thin line at the top.

However, for the women who risk their lives with unsafe abortions and who are most in need of such advice, since none is available they are more likely to fall into a pattern of repeat abortions represented by the thick red line at the bottom.

The track at the bottom is intended to display an important element. Except for the few women who are fortunate enough to receive counselling from private practitioners, all others experience no reinforcement of the moral guidance and knowledge-based instruction. Thus, the track is shown growing ever fainter.

The criminal abortion law persists because those who have the voice to change it have no need to do so; and because those who have the need to change the law have no voice to do so.

The criminal law is a catastrophe. It does not prevent abortions. It does not change behaviour. It puts poor women's lives at risk. It leaves other women vulnerable to the scruples of medical practitioners in an unregulated clandestine service. It is a law that no one cares to obey and no one dares to enforce.

I am unable to identify any merit in the criminal abortion law as it operates in poor countries.
Is there any way in which we could eliminate the social injustice? Could we get rid of the five boxes that glare at us? Can we reduce the incidence of repeat abortions?

Is there a better way? Is there an option? I think so. Let us look at that option.

We need to spend no time on the social situation; It is the same social situation it remains identical to the one we had before. The story is the very same.

I would like us to explore a different legal response.

Again we start with the dotted line depicting the law. I want to propose a different legal response with just four steps (Figure 4).

If we assume a regime of liberal, legal abortion, with access to all women, then there are only two options to continue an unwanted pregnancy or to end it. In the absence of legal constraints, we hope that the choice to continue would be voluntary. While there is no assurance of this, the most we can do from a public policy perspective is to remove any legal constraint. If the woman makes this choice voluntarily we would expect the positive outcomes listed.

The other option is at Step 6, where she requests a termination. Once she makes that request, she has access to counselling (Step 7) to ensure that she is certain of her decision and fully aware of the options available to her. Please note that we have been careful to call this pre-decision counselling not preabortion counselling. The latter name seems to presume a decision to have an abortion. 


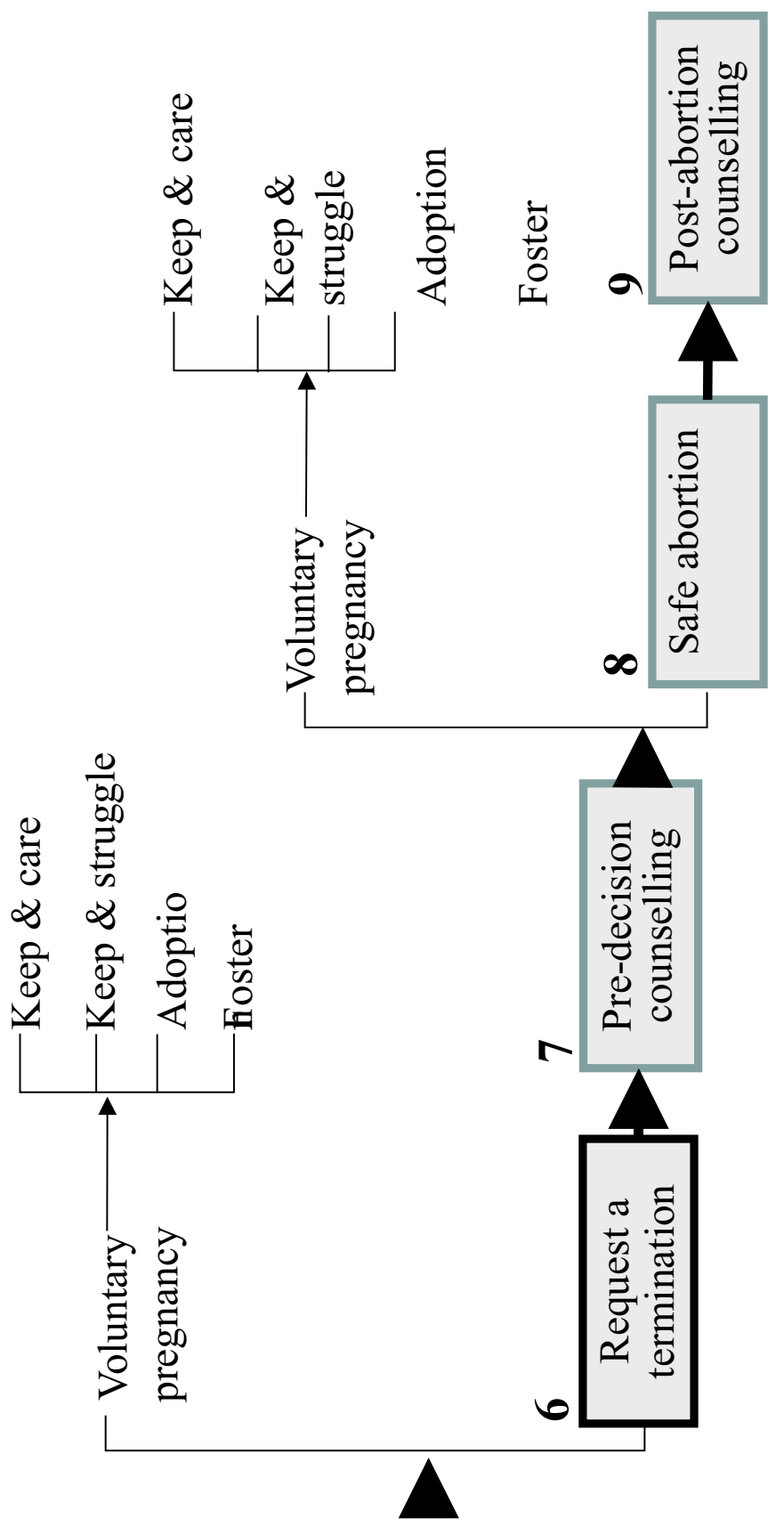


After counselling, she may decide to continue her pregnancy. If so, we would expect the same measure of satisfaction to attend her decision, namely, that she will try to raise the child herself, rely on fostering or decide to give the child for adoption.

This provision for access to counselling and choice is not trivial. The provision of a regime of legal choice is not the same as 'promoting' abortion. It is promoting informed choice. We have seen that the real achievement of the criminal law is not to prevent abortions but that it drives poor women into dangerous risky behaviour. Legal abortion would remove that coercion and ensure access to safe services.

If she decides on terminating her pregnancy, she is at Step 8. There she has access to a safe medical abortion. Since abortion is widely legal, the government would have made arrangements for training and the introduction of modern methods. Currently throughout the public service the methods in use are typically archaic and involve an almost complete reliance on general anaesthesia and $\mathrm{D} \& \mathrm{C}$. Creating a legal regime opens the door for MVA and medical abortion, neither of which involves general anaesthesia.

Once the procedure is complete the woman would have access to post-abortion care at Step 9. The intent of this service is to support the woman, and where appropriate her partner, in making the best choice of contraceptive method.
In this process there are two explicit stages directed at the individual's behaviour. At Step 7 there is explicit concern with the woman's emotional comfort and at Step 9 there is a similar focus on the adoption of contraceptives. If a new law is to have the impact of reducing repeat abortions and ultimately the overall incidence of abortion, it is in these two stages that the investment is critical. This is the challenge. By comparison, the task of introducing modern medical techniques for the treatment is quite simple.

Let us now put this legal option along with the social problem and see how they match up (Figure 5). The red boxes have gone. The cruel rich-poor stratification is no longer there. The care that was once exclusive to those who could afford private practitioners is now generally available. The net result is that the thin green line has become the predominant pattern. The red line remains, but it is far smaller. Eliminating that red line remains a challenge.

And the track at the bottom has been transformed. The provision of pre-decision and post-abortion counselling has served to reinforce the same moral tenets about the value of life and the need for contraceptive knowledge that were given earlier. Contrary to the notion that legal abortion 'undermines the social fabric of society,' we see the very opposite. The provision of professional counselling serves to reinforce the values of the community.

So in spite of some fading of the moral guidance and information provided earlier, these are eventually strengthened again during counselling. 


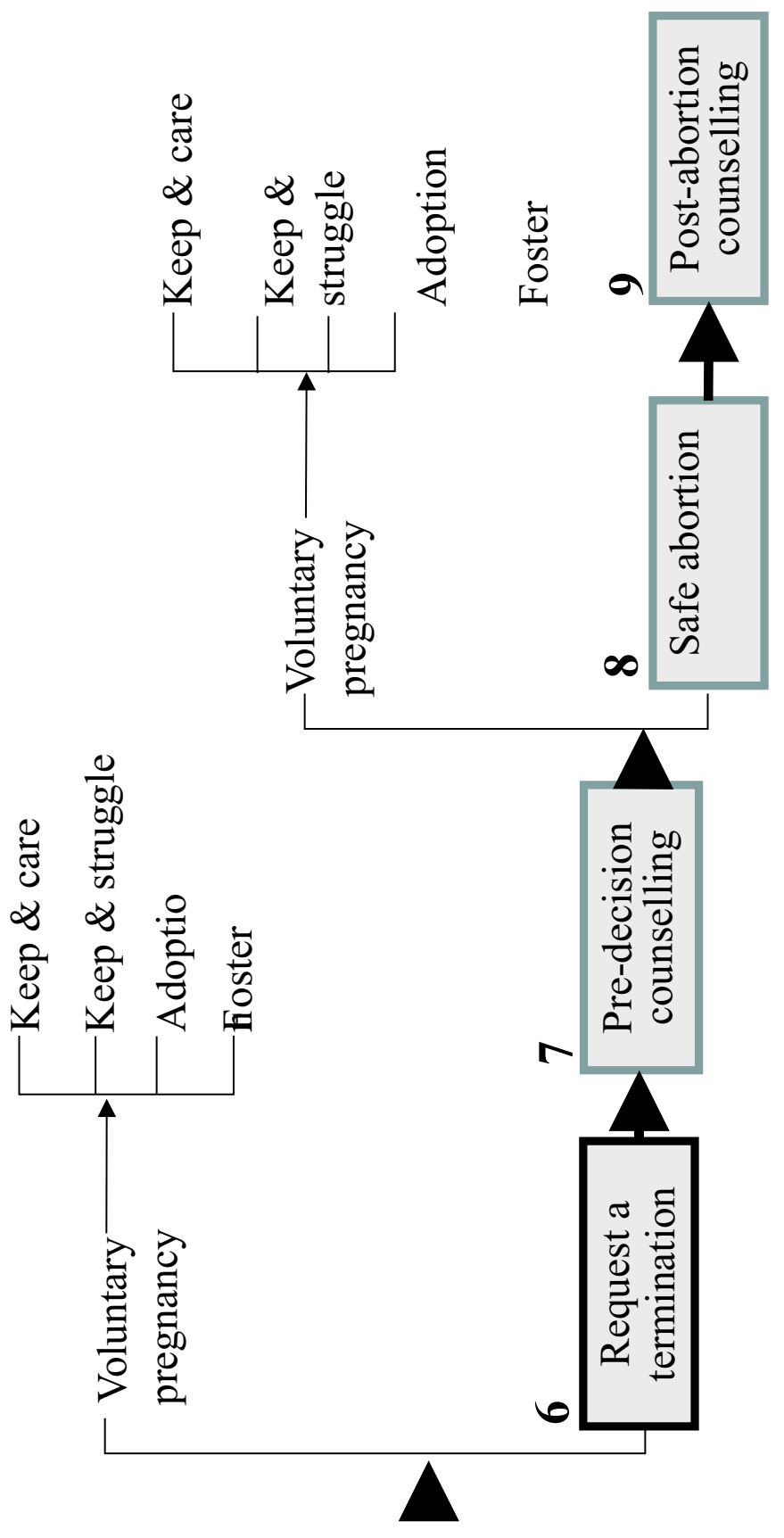


Let us put all the charts together so we can appreciate the difference. Control has not worked. The restrictive law made the problem worse. While it seems counterintuitive, we have nothing to lose by trying a regime of legal abortion. The liberal law offers the prospect of make the situation much better. It offers too much promise to be ignored. The shift in law that is proposed here, from control to regulation, is not unique.

The US tried to control alcohol by prohibition. It was a disaster of legendary proportions. They eventually turned to legalisation. While it is less known, the same was true of cigarettes. They were also prohibited in several states. The consequences were the same corruption, crime and a huge underground industry. By making cigarettes and alcohol legal and relying on regulation instead of prohibition the government succeeded where it had always failed. Today in the US, there are more ex-smokers than smokers.

A regime of legal abortion on the civil code has enormous potential. It can readily empty our hospitals of unsafe abortions. This would radically improve women's reproductive health and simultaneously save substantial sums in public hospitals. It can make a major contribution to reducing repeat abortions. And in the medium to long term it can help to reduce the need for and recourse to abortions.

Why should we hold to a law that is a proven disaster when we have a chance of making a change to improve women's health, reduce abortions and save substantial sums of the hospital's meagre budget?
What is it that prevents us from acting in a situation that is so patently obvious? We are paralyzed by our confusion of morality and legality. We fail to see these as two separate entities. Erroneously, we have been trapped into equating legal with good and right and illegal with bad and wrong. Public policy migrates across all of these four boxes.

\begin{tabular}{|l|l|l|}
\hline & \multicolumn{2}{|c|}{ MORALITY } \\
\hline & Bad,Wrong & Good, Right \\
L & Legal & \\
A & Illegal & \\
W & La \\
\hline
\end{tabular}

Most constitutions separate religion and the state precisely because in plural societies serving the common good is a more complex calculus than a simple right-wrong dichotomy. When the US made alcohol legal its intention was not to declare alcohol a good thing, but to rid society of the public mischief caused by the illegal trade. The same is true of countries that have made gambling, prostitution, and homosexuality legal. They are not declaring these to be good or right: they are admitting that consenting adults must be free to live free of the intrusion of the state and admitting that the effort to prohibit these behaviours is futile and results in even greater social harm.

One of the alarming dangers of the current era is the increasing grasp of state power by religious leaders. This is an ugly spectre of intolerance. Religious dogma is not the appropriate cauldron for state policy. We must not confuse democracy with theocracy, nor limit our sense of morality to religious 
dogma. Women and minorities have invariably been atrociously served by religious regimes. Religious leaders are driving for a captivity of the legislative chambers: they are seeking to legislate the sexual morality that they have failed to inculcate. That is an impossibility. That is also not the role of the law.

There must be space for reason and doubt in making public policy. Dogma, whether ideological or religious, is intolerant of both. A retreat from science to dogma is an unhealthy direction for plural societies that strive for inclusion, fairness and justice for all groups.

Let me return briefly to the questions we posed at the outset.

Do restrictive abortion laws secure a reduction in abortions? No, they don't. No matter how repressive these laws are women determined to end an unwanted pregnancy will risk their lives. The number of abortions increases year after year in spite of restrictive laws.

How well do criminal abortion laws protect the sanctity of life? Obviously this is another area of gross failure. This follows as a corollary of the first. Restrictive laws endanger poor women's lives, fail to prevent abortions and so fail to safeguard unborn life.

Are restrictive laws equitable across all classes of women? We have seen that one feature of restrictive laws is that they are a source of horrendous social injustice. They are no threat to non-poor women but a great danger to poor women. It is poor women who die because of restrictive laws that force them to risk their lives in unsafe procedures.

Do liberal abortion laws result in a weakening of the moral fabric of society? As we have seen, restrictive laws by themselves do nothing to preserve the moral fabric of society. On the contrary, the so-called moral fabric has been weakening under restrictive laws. We have shown that there is real potential under liberal civil law to provide counselling that would reinforce the moral messages of our social institutions.

Do liberal abortion laws result in an explosion of abortions? There is commonly a huge increase in the number of reported abortions following legalisation. But we should rush to distinguish between actual abortions and reported abortions. Obviously under restrictive criminal law only a handful of abortions are reported. Legalisation is commonly accompanied by a requirement for reporting. It is likely, however, that in the first few years following legalisation, there will be a small increase in the actual number of abortions. These tend to decline as the uptake for contraceptives increases with counselling. Countries with very liberal laws have some of the lowest abortion rates in the world. 
24 African Journal of Reproductive Health
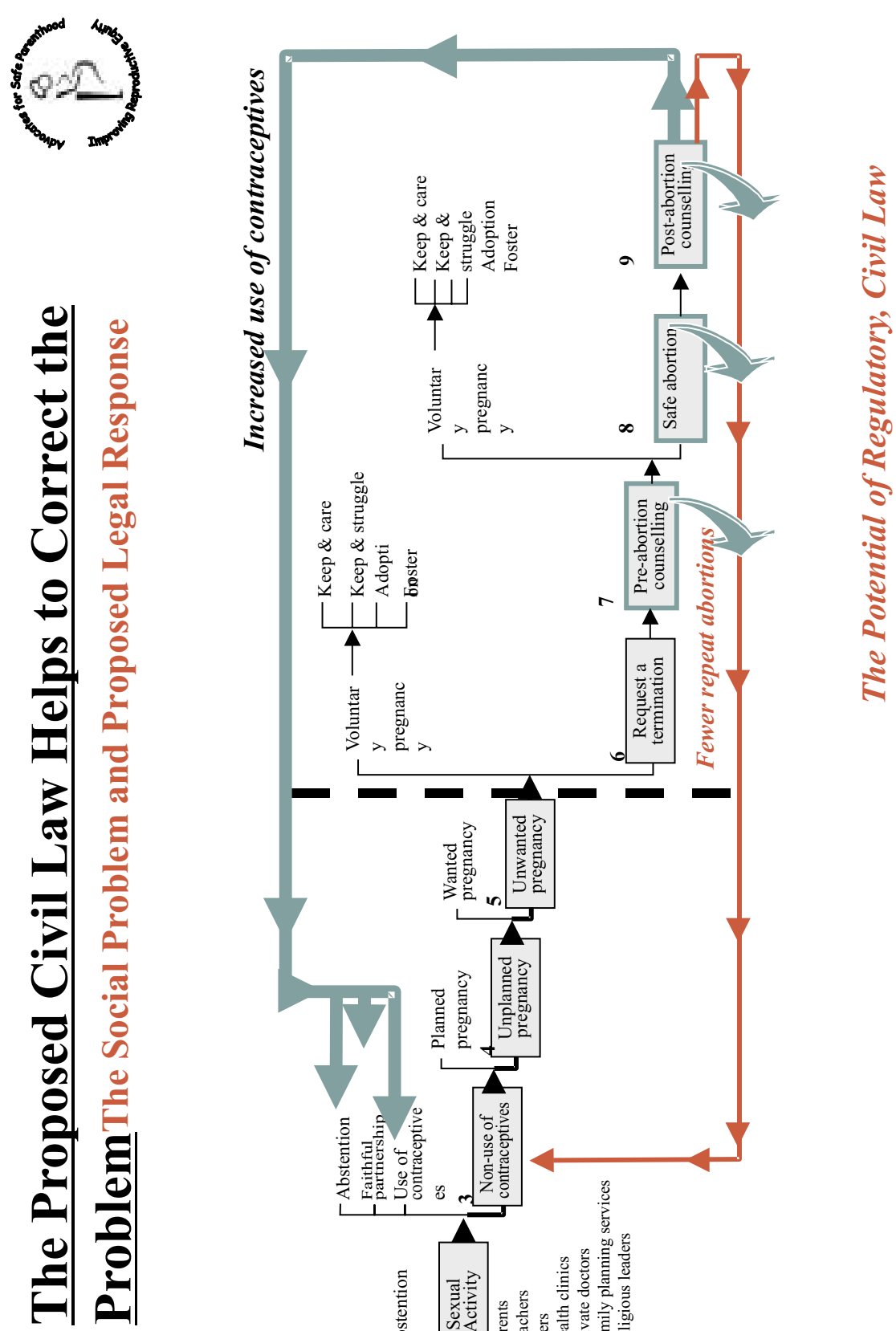
How does either approach affect the physical and emotional health of women? The stigma of abortion associated with the criminal law is a source of trauma for women seeking care. One prospect of legal abortion is that it opens the window for creating far more wholesome attitudes toward women's autonomy. In so far as the law helps care providers to treat women with compassion, dignity and sensitivity, the liberal regime has the prospect for significantly enhancing women's emotional health.

We must have the courage to look at the logic of the two legal regimes and make the informed moral and scientific decision that is imperative (Figure 6). Any retreat from that is a denial of social justice. 


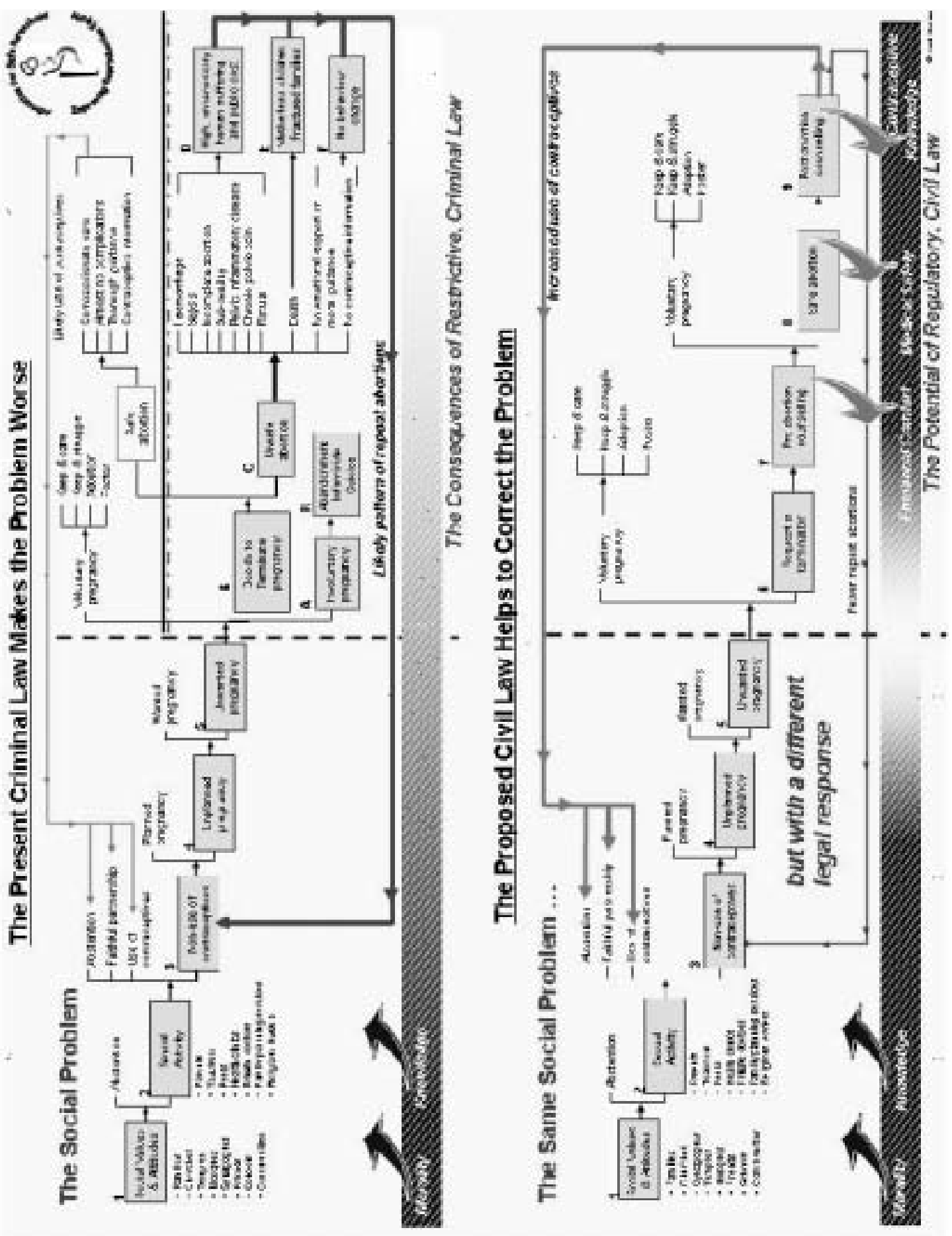

